\title{
Analyzing Communication Competences in Professional Mathematics of University Students by Using GRA
}

\author{
Hsiu-Lan $\mathrm{Ma}^{1, \text { a }}$, Der-Bang $\mathrm{Wu}^{2}$, b and Yu-Kuang Cheng ${ }^{3, \mathrm{c}}$ \\ ${ }^{1}$ Ling Tung University, No. 1 Ling-Tung Road, Nantun District, Taichung \\ 40852, Taiwan \\ ${ }^{2,3}$ National Taichung University of Education, No. 140, Min-Sheng Road, \\ West District, Taichung, 40306 Taiwan \\ ahlma@hotmail.com.tw, bwudb@hotmail.com, ${ }^{c}$ mike8826us@yahoo.com
}

\begin{abstract}
This study analyzed the Communication ability of professional mathematics of university students of technology by using Grey Relational Analysis (GRA). Current results of this study not only identify the hardest and easiest problems for students, but also show how proposed GRA provides a novel approach to educational testing.

Keywords:Grey Relational Analysis (GRA), Communication, Professional mathematics, Mathematics, Knowledge
\end{abstract}

\section{Introduction}

We live in a mathematical world [1]. Whenever we decide on a purchase, choose an insurance or health plan, or use a spreadsheet, we rely on mathematical understanding [1]. While mathematics is an integrated arena of study, often students view concepts as disjointed chunks of information with little connection or relation [1]. According to National Council of Teachers of Mathematics (NCTM) [1], students from prekindergarten through grade 12 should see and experience the rich interplay among mathematical topics, see and experience this interconnectedness between mathematics and other domains, and also be able to connect mathematics to their own interests [1]. Viewing mathematics as a whole, such as web of linked concepts, will help students to learn that mathematics is not a set of isolated skills and arbitrary rules [1]. "Connection" is the term used in the national mathematics curriculum of Taiwan for addressing the issue of the relationships between mathematics and the other subjects.

In the nine-year mathematics curriculum of 2008 for primary and junior-high school [2], there is a topic called "Connection." The first part of the "Connection" is called "reception," which includes the following competences that students need to possess.

C-R-01 Can aware the daily contexts that are related to mathematics. 
C-R-02 Can aware the Connect between mathematics and the other domains.

$C-R-03$ Can understand that mathematics can be applied to natural or social sciences.

C-R-04 Can provide concrete examples of how mathematics promote human cultural development.

The second part of the "Connection" is called "transformation," "problem solving" followed. The third part of the "Connection" is called "Communication,"

In the present high-school curriculum, one of the goals of mathematics curriculum is to cultivate student necessary mathematics knowledge and skills to improve daily practices and to learn related school subjects. One of the core competences of mathematics curriculum is "connection”: To integrate internal mathematical knowledge and to connect to the concrete world [3].

Therefore, this paper aims to analyze the Communication ability of professional mathematics of university students by using Grey Relational Analysis (GRA).

\section{Methods and Procedures}

\subsection{Participants and Design of Study}

In this study, a questionnaire of 10 Problems was conducted and 207 students of University of Technology in Taiwan were asked to respond.

\subsection{Instrument}

This study uses the Ma-Wu's Test of Competences in Professional Mathematics of University Students (MWTCPM), which was specifically designed for this project, due to no suitable Chinese instruments available [10-15]. There are 10 multiple-choice problems. Each problem contained 4 sub-problems which collated the connection's 4 sub-steps: "reception", "transformation and problem solving", “communication", as well as "evaluation". The score for each sub-problem is one point. So, there are 4 points for each problem and totally 40 points in each test. However, in this paper, only the score on the third sub-step is analyzed.

\section{Grey Relational Analysis}

Such analysis is depicted in this section, starting with essential definitions. What follows are important theorems that involved in this model. Construction of GRA model is briefly described. For more details refer to the works of Yamaguchi et al. [23-32]. Details of GRA model could refer our previous works [33-34]. 


\section{Data and Variables}

This study focuses on sample data of 207 students mentioned in the previous section. Based on overview of prior literature [21-27], we derive broader coverage of significant variables for pictorial patterns (P1-3 means the question of sub-step 3 in Problem 1).

Grey Relational Analysis. Sample data on the above-mentioned problems of MWTCPM are used to calculate Minkowski distance of $L_{p}$ norm. Grey relational grade (Gamma) values are computed using current GRA model in Table 1. Problems in these tables are sorted by average values of gamma.

Table 1. Gamma values for Problems in “communication” ability.

\begin{tabular}{cc} 
Problems & Gamma \\
\hline P4-3 & 0 \\
P3-3 & 0.0492 \\
P8-3 & 0.0994 \\
P5-3 & 0.112 \\
P9-3 & 0.3519 \\
P10-3 & 0.4229 \\
P1-3 & 0.4374 \\
P7-3 & 0.4374 \\
P2-3 & 0.9247 \\
P6-3 & 1 \\
\hline
\end{tabular}

From Table 1, Problem 4 [problem concerned discount of ticket of high-speed real way] proves most difficult among 10 problems, followed by Problem 3 [problem concerned insurance rate], Problem 8 [problem concerned mortgage], and Problem 5 [problem concerned discount of restaurant]. The authors wish to discern why university students have difficulty with these formats of exchange patterns. Researchers might consider this as their research interest.

On the other hand, GRA analysis shows Problem 6 [problem concerned sales profit] as easiest for students, followed by Problem 2 [problem concerned buy one 
get one] Problem 7 [problem concerned unemployment rate], and Problem 1 [problem concerned supermarket profit]. The authors wish to learn why university students have no difficulties with these formats of profit. The diagram depicts smooth distribution of gamma values from 0 to 1 .

Figure 1 graphs average values of gamma, in which each point represents a question studied.

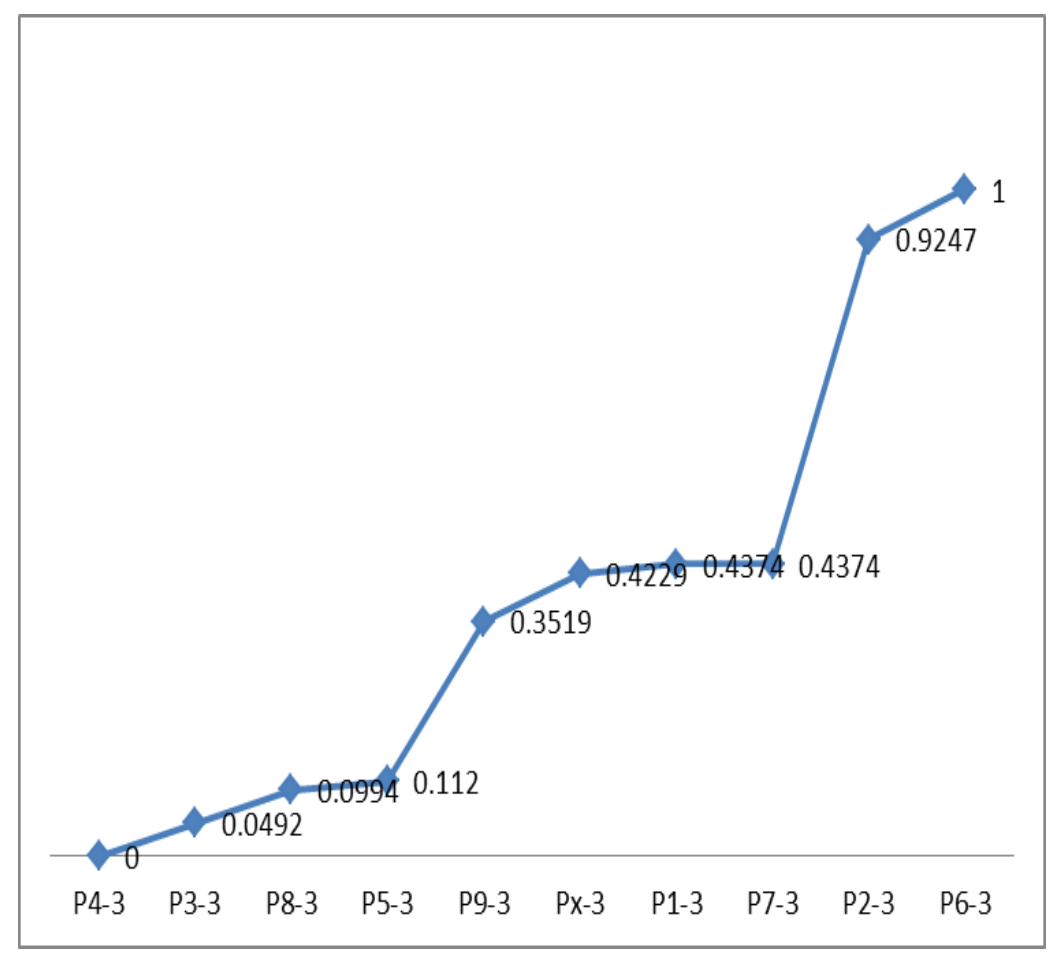

Figure 1. Pattern of average grey relational grade (Gamma) for “communication” ability

\section{Conclusions}

Results of this study identified the easiest and most difficult concepts for university students; it is crucial to ferret out reasons for this outcome. The authors investigate why university students have difficulties in identifying the problem concerned rates (unemployment rate, sales profit and exchange rate of area units). One reason might be that the problem concerned rates are rarely shown in textbooks and/or professional mathematics. Researchers might consider it as their research interest and use Interpretive Structure Modeling (ISM) of Grey System, Fuzzy Measure [29-35], Fuzzy C-means [35-39], or the grey model $\operatorname{GM}(h, N)$ [29-35], to analyse the Communication ability of professional mathematics of university students. In the future, data on communication and evaluation can be 
analysed by Fuzzy Measure, Fuzzy C-means, GRA, or Grey Model GM $(h, N)$ also. Finally, we suggest that professors work the connection relative to professional mathematics, such that students apply math they learn and augment their long-life learning.

\section{Acknowledgments}

This research was funded by the National Science Council of Taiwan under Grant No. NSC 100-2511-S-275 -001-MY3. Opinions expressed do not necessarily reflect the views of NSC.

\section{References}

[1] National Council of Teachers of Mathematics (NCTM) Curriculum and Evaluation Standards for School Mathematics (Reston, Virginia, NCTM 2000).

[2] Ministry of Education in Taiwan, The nine-year-integration mathematics curriculum for primary and junior-high schools. (in Chinese) Retrieved from http://teach.eje.edu.tw/9CC2/9cc_97.php 2008.

[3] M J Coles and W D Robinson (Eds.) Teaching Thinking (Bristol: The Bristol Press 1989).

[4] S Krulik and J A Rudnick Reasoning and problem solving: A handbook for elementary school teachers (Needham Heights, Mass: Allyn and Bacon 1993).

[5] S Krulik and J A Rudnick In L. V. Stiff and F. R. Curcio (Eds.) Developing Mathematical Reasoning in Grades K-12 (National Council of Teachers of Mathematics 1999) pp. 138-145.

[6] P. G. O’Daffer, and B. A. Thornquist In P. A. Wilson (Ed) Research Ideas for the Classroom: High School Mathematics (New York: MacMillan Publishing 1993) pp. 39-56.

[7] R Audi Practical reasoning (London: Routledge 1991).

[8] I Murdoch The Sovereignty of Good London (Routledge/Ark 1970).

[9] C Diamond in M. Antonaccio, and W. Schweiker (Eds.) Iris Murdoch and the Search for Human Goodness (Chicago, University of Chicago Press 1996). 
[10] H L Ma (2000 school year Teacher Normal Education Thesis Bulleti, vol. 2) 2000, pp. 711-742.

[11] H L Ma (Chinese Journal of Science Education vol. 9-4) 2001, pp. 375-399.

[12] H L Ma (Chinese Journal of Science Education vol. 12-1) 2004, pp. 53-81.

[13] H L Ma (Chinese Journal of Science Education vol. 15-4) 2007, pp. 387-416.

[14] H L Ma, D B Wu, Y K Cheng, \& J W Chen (Advanced Materials Research vol. 971-973) 2014, pp. 2705-2708.

[15] H L Ma, C I Jen, S H Lin, \& D B Wu (Advanced Materials Research vol. 993) 2014, pp. 774-777.

[16] J S Jau (Master thesis, Department of Automation Engineering and Institute of Mechatronoptic Systems, Chienkuo Technology University, Changhua 2008).

[17] J L Deng Grey System (China Oceans Press, China 1988).

[18] M Nagai and Yamaguchi D Elements on Grey System Theory and Applications (Kyoritsu-Shuppan, Tokyo 2004).

[19] K L Wen Grey Systems: Modeling and Prediction (Yang’s Scientific Research Institute, Tucson 2004).

[20] K L WenApply MATLAB in grey system theory (CHWA Publisher, Taipei 2006).

[21] K L Wen, Wang C W, and Yeh C K (Proc. IEEE SMC 2007 Conference, Montreal) 2007, pp. 2271-2275.

[22] Chen S O, Huang C C, You M L, and. Kung C Y (Proc. Frontiers in the Convergence of Bioscience and Information Technologies, Korea 2007).

[23] K L Wen, Choa C S, Chang H C, Chen H Y, and Wen H S (Wu-Nan Culture Enterprise, Taipei, Taiwan 2009).

[24] D Yamaguchi, G D Li and M Nagai (Journal of Grey System vol. 10-3) 2007, pp. 169-182.

[25] S F Liu, Y Lin 2005 Grey Information (Springer, London). 
[26] You M L, Wang C W, and Yeh C K (Journal of Grey System vol. 9-1) 2006, pp. 57-64.

[27] D Yamaguchi, T Kobayashi, K Mizutani, Akabane T, and M Nagai (Japnanese Journal of Japan Society of Kansei Engineering vol. 4-2) 2004, pp. 101-106.

[28] D Yamaguchi, G D Li, and M Nagai 2005 (Journal of Grey System vol. 8-2) pp. 167-178.

[29] D B Wu and H L Ma (Journal of Grey System vol. 12-4) 2009, pp. 161-168.

[30] D B Wu and H L Ma (Applied Mechanics and Materials vols. 44-47) 2011, pp. 3922-3926.

[31] H. C. Liu, C. C. Chen, D. B. Wu, T. W. Sheu WSEAS transactions on systems and control, 4(8) 2009, pp. 359-368.

[32] H C Liu, D B Wu, Y D Jheng and T W Sheu (WSEAS Transactions on Information Science and Applications vol. 6-6) 2009, pp. 1061-1070.

[33] H C Liu, D B Wu, J M Yih and Liu S W (WSEAS Transactions on Biology and Biomedicine vol. 4-7) 2007, pp. 93-98.

[34] H C Liu, D B Wu, and H L Ma (WSEAS Transactions on Biology and Biomedicine vol. 4-7) 2007, pp 99-102.

[35] H C Liu, J M Yih, W C Lin and D B Wu (Journal of Multiple-Valued Logic and Soft Computing vol. 15 no. 5, 6) 2009, pp. 581-595. 